\title{
Carcinomatous meningitis: antibody-guided therapy with I-131 HMFG1
}

\author{
R P Moseley, J C Benjamin, R D Ashpole, N M Sullivan, J A Bullimore, H B Coakham, \\ $\mathrm{J}$ T Kemshead
}

\begin{abstract}
Seven patients with carcinomatous meningitis were administered intrathecal I-131 labelled monoclonal antibody HMFG1. Clinical responses were seen in two patients, with a long term survivor at 32 months. Aseptic meningitis occurred in $4 / 7$ patients, but more serious toxicity was observed in the form of seizures (2/7 patients) and myelosuppression (3/7 patients). Partial obliteration of the subarachnoid space was identified as a potential problem in patients with advanced disease.
\end{abstract}

The development of monoclonal antibodies defining tumour associated antigens has significantly enhanced the field of diagnostic histopathology..$^{12}$ As a natural extension of their success as immunocytochemical reagents, extensive investigation has explored their potential as vectors for targeting radionuclides, ${ }^{34}$ toxins $^{56}$ or drugs ${ }^{7}$ to tumours. In animal xenograft tumour models, specific targeting of radioimmunoconjugates to tumour sites has been demonstrated. ${ }^{89}$ Therapeutic effect has also been observed in these models as evidenced by shrinkage and even cure of tumours. ${ }^{10-12}$

In contrast to animal studies, the intravenous administration of monoclonal antibody immunoconjugates into patients with tumours has been consistently disappointing. In most studies, the percentage of the total injected dose of immunoconjugate localising within tumour tissue has been extremely low (approximately $10^{-3} \%$ of the injected dose per gram of tumour) and this has been attributed to several factors. Firstly, the volume of disa tribution of these radiopharmaceuticals in humans is several orders of magnitude greater than in laboratory animals and this dilutional effect clearly reduces the concentration of immunoconjugate at tumour sites. ${ }^{13}$

Secondly, the penetration of immunoconjugate into tumours may be restricted by limited permeability of these macromolecules across lipid membrane blood/tumour barriers. ${ }^{13}$ Other contributing factors cited have included the presence of tumour-shed antigens, ${ }^{14}$ and the sequestration of blood pool immunoconjugate within abdominal viscera. ${ }^{13}$ Many of these problems are circumvented by the direct instillation of these reagents into body cavities where tumour cells are directly exposed to high concentration of immunoconjugate. These techniques were pioneered in the coelomic cavities, ${ }^{15-17}$ and subsequently evaluated in the subarachnoid space of patients with neoplastic meningitis. ${ }^{18}$ Experience to date with intracavitary monoclonal antibody radioimmunotherapy has largely been with iodine-131 and yttrium-90. These predominantly beta-emitting radionuclides deliver short range energy to micrometastases, whilst sparing normal body tissues. Neoplastic meningitis is characterised by the existence of thin sheets of leptomeningeal tumour and free floating malignant cell clusters within the subarachnoid space. It is therefore theoretically amenable to specifically targeted short range radiation delivered via the CSF pathways. In preliminary studies of antibody guided radiation in neoplastic meningitis, demonstrable therapeutic responses were seen in patients with relatively radiosensitive neuro-ectodermal and lymphoid tumours. ${ }^{1819}$ The efficacy of this method for the treatment of neoplastic meningitis secondary to carcinoma (carcinomatous meningitis) is also currently being evaluated and we report here the results obtained with seven patients treated by intrathecal administration of I-131 labelled monoclonal antibody HMFG1.

\section{Methods \\ Antibody}

The antibody HMFG1 was developed against the human milk fat globule ${ }^{20}$ and binds to an epitope on the high molecular weight glycoprotein (polymorphic epithelial mucin, PEM). Tissue distribution of this antigen is limited to a variety of normal and neoplastic derivatives of glandular epithelium. ${ }^{21}$ Purified HMFGl antibody (Unipath) in phosphate buffered saline was radiolabelled with the stationary phase chloramide iodogen ${ }^{22}$ to a specific activity of $5-10 \mathrm{uCi} / \mathrm{ug}$ of protein. Structural integrity of radioimmunoconjugates was assessed by trichloroacetic acid (TCA) precipitation and gel filtration chromatography with Sephacryl S300. Biological function of immunoconjugates was estimated by determination of the immunoreactive fraction by radiobinding assay at antigen excess. ${ }^{2324}$ All radiopharmaceuticals were sterilised by millipore filtration before administration to patients.

\section{Patient selection and management}

Seven patients with carcinomatous meningitis were studied. Patients included in this study had either failed an adequate trial of conventional therapy or had been referred directly 
following diagnosis. Patients and their relatives were fully informed of the experimental nature of this work and provided their written consent. The study was also approved by the Frenchay Hospital Ethical Committee. In all patients, a full clinical evaluation of disease was performed, supported by haematological and biochemical assessment. Cranial CT scanning was performed to exclude intracranial mass lesions. Pan-myelography and CT cisternography were subsequently employed to ascertain the patency of the CSF pathways. Immunocytochemistry of CSF was performed firstly to confirm the diagnosis of carcinomatous meningitis and secondly to demonstrate the presence of HMFGl defined antigen (PEM) on malignant cells. In all patients, the diagnosis of carcinomatous meningitis was also confirmed by the demonstration of soluble PEM antigen in CSF. ${ }^{25}$

Thyroid blockade was immediately started in all patients and continued for approximately one month following administration of immunoconjugate. Glucocorticoids (dexamethasone $1 \mathrm{mg}$ three times daily) were also administered in an attempt to suppress aseptic meningitis which was seen in earlier patients following intrathecal administration of immunoconjugate. ${ }^{18}$ A single intrathecal administration of immunoconjugate was performed via an Ommaya reservoir ventriculostomy following an isovolumetric withdrawal of CSF. Administered radioactivity dosage in patients $1-7$ was $55,55,58,56,30,60$, and 54 $\mathrm{mCi}$ respectively. Patients were nursed in radioprotective facilities until levels of radioactivity had fallen sufficiently to allow conventional nursing care.

\section{Imaging}

Immunoscintigraphy of the neuraxis was performed with a General Electric MaxiCamera $400 \mathrm{~T}$ equipped with a high energy parallelhole collimator and linked to a DEC PDP $11 / 34$ computer with gamma 11 software. Patients were scanned as soon and as often as their clinical condition permitted. In cases 2 and 3, clinical circumstances prevented acquisition of scanning biodistribution data.

\section{Evaluation of clinical response}

Patients were evaluated for response if they had received neither chemotherapy nor radiotherapy to all evaluable sites within the preceding six weeks. These conditions were waived if the patients had clear evidence of disease progression in the intervening period.
All patients in this study were initially considered clinically evaluable by these criteria. Response was assessed at three-monthly intervals by clinical examination, cranial CT scanning and cytological examination of CSF. In addition, estimation of PEM in serum and CSF at three months following therapy was performed in cases $1,3,4,5$, and 7 .

\section{Results}

Seven patients with carcinomatous meningitis were studied, with a range of primary tumour sites (table 1 ). The age range was $36-60$ years and there were three males and four females. The immunoreactivity of administered conjugates exceeded $50 \%$ in all patients.

\section{Immunoscintigraphy}

I-131 activity was observed within the cerebral ventricles and craniospinal subarachnoid space in all patients who had gamma scintigraphy. However, neuraxial distribution of radionuclide was always irregular and incomplete. Paucity of radionuclide was commonly observed over the cerebral hemisphere convexities or within the basal subarachnoid cisterns (fig 1). Sites of increased neuraxial isotope uptake were frequently demonstrated at clinically suspected and/or radiologically demonstrated sites of disease (tables 2 and 3 ).

\section{Clinical response to therapy}

Pre-treatment status and clinical responses in all seven patients are shown in tables 4 and 5 . Clinical responses were assessed in terms of neurological response, CSF response and survival. Neurological response was categorised as complete (CR) if there was total resolution of symptoms and signs. Partial response

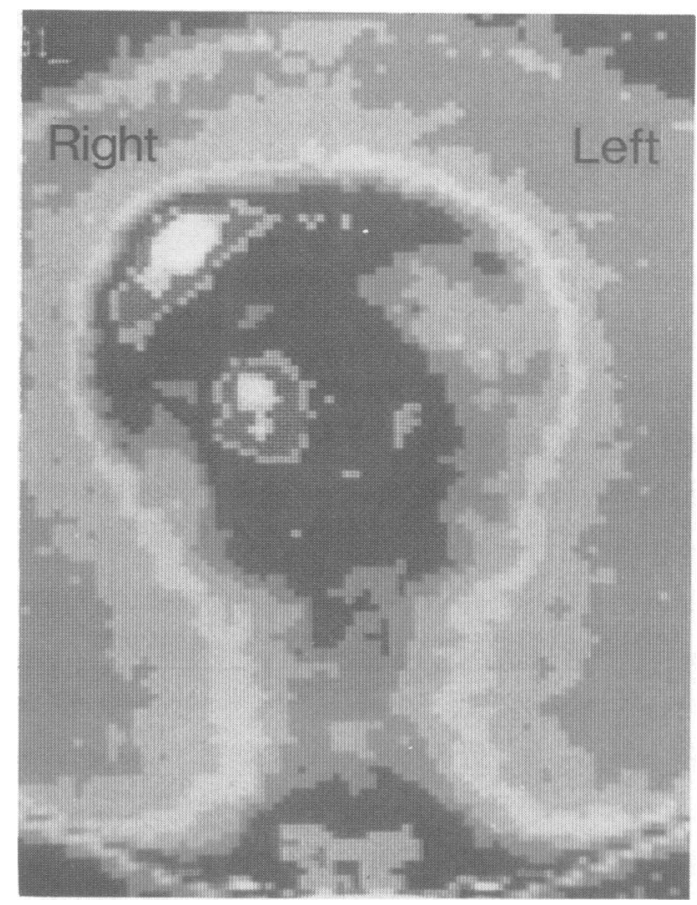

Figure 1 Cranial scintigram of case 5 at eight days revealing paucity of isotope activity over left cerebral hemisphere convexity. Necropsy studies revealed bilateral hemisphere disease involving the leptomeninges.
Table 1 Clinical parameters of patients with carcinomatous meningitis

\begin{tabular}{lllll}
\hline Patient & $\begin{array}{l}\text { Age in } \\
\text { years }\end{array}$ & Sex & Primary tumour & $\begin{array}{l}\text { Sites of clinically } \\
\text { apparent extraneuraxial } \\
\text { disease }\end{array}$ \\
\hline 1 & 48 & F & $\begin{array}{l}\text { Ovarian carcinoma } \\
\text { Bladder carcinoma }\end{array}$ & $-\overline{\text { Liver }}$ \\
3 & 60 & F & Breast carcinoma & Lung \\
4 & 44 & M & Large cell lung carcinoma & Lung \\
5 & 57 & M & Lung adenocarcinoma & Breast carcinoma \\
6 & 41 & M & Large cell lung carcinoma & Lung \\
7 & 36 & & &
\end{tabular}


Table 2 Intrathecal therapy: diagnostic radiology

\begin{tabular}{ll}
\hline Patient & CT/myelography \\
\hline 1 & $\begin{array}{l}\text { Excess CSF over cerebral hemisphere convexities } \\
\text { and nodular leptomeningeal tumour involving } \\
\text { cauda equina }\end{array}$ \\
2 & $\begin{array}{l}\text { Hydrocephalus } \\
\text { Normal }\end{array}$ \\
3 & $\begin{array}{l}\text { Hydrocephalus. Nodular leptomeningeal tumour } \\
\text { involving cauda equina } \\
\text { Multiple low density areas seen over cerebral } \\
\text { hemisphere convexities. Nodular leptomeningeal } \\
\text { tumour involving cauda equina } \\
\text { Hydrocephalus. Diffuse contrast enhancement } \\
\text { over left cerebral hemisphere convexity }\end{array}$ \\
6 & $\begin{array}{l}\text { Nodular leptomeningeal tumour involving cauda } \\
\text { equina }\end{array}$ \\
\hline
\end{tabular}

(PR) implied some improvement in neurological symptoms and signs. When neurological symptoms/signs remained stable or deteriorated, this was categorised as no response (NR). CSF response was assessed on the presence or absence of malignant cells seen on cytological examination. A complete response (CR) indicated complete eradication of malignant cells from two daily consecutive CSF preparations. A partial response (PR) indicated a sustained reduction of malignant cell count in two daily consecutive CSF preparations. When malignant cell counts remained unaltered or increased, it was considered that no response (NR) to therapy had been demonstrated. In cases $1,3,4,5$, and 7 , an additional parameter of CSF response was obtained by estimation of HMFG1 (PEM) mucin in serum and CSF before and at three months following therapy.

Patient 2 died suddenly at 72 hours and was therefore clinically inevaluable for response. The remaining six patients were considered clinically evaluable for response. Neurological responses were seen in $2 / 6$ patients (cases 1 and $3)$. CSF responses were seen in $1 / 6$ patients (case 3 ). The latter patient remains in complete remission at 36 months, having received no additional treatment. In $4 / 5$ patients, CSF levels of HMFG1 (PEM) mucin increased following therapy (cases $1,4,5$, and 7 ), indicating progressive disease within the central nervous system (fig 2 ). In case 3 , a positive diagnostic assay result became negative after therapy. In this same group of patients with the exception of case 3, serum HMFG1 (PEM) mucin increased following therapy, indicating progressive systemic disease (fig 3). Serum levels of HMFG1 (PEM) mucin in case 3 remained approximately constant, indicating stable systemic disease.

Table 3 Intrathecal therapy: immunoscintigraphy

\begin{tabular}{llll}
\hline Patient & $\begin{array}{l}\text { Extent of } \\
\text { neuraxial } \\
\text { distribution }\end{array}$ & $\begin{array}{l}\text { Sites of increased } \\
\text { neuraxial distribution }\end{array}$ & $\begin{array}{l}\text { Sites of } \\
\text { extraneuraxial } \\
\text { distribution }\end{array}$ \\
\hline 1 & Incomplete & $\begin{array}{l}\text { Cranial vertex } \\
\text { Lumbar/sacral spine }\end{array}$ & $\begin{array}{l}\text { Thyroid } \\
\text { Abdominal Foci }\end{array}$ \\
2 & - & - & - \\
3 & - & Lumbar/sacral spine & Spleen \\
5 & Incomplete & $\begin{array}{l}\text { Left hemisphere convexity } \\
\text { Lumbar/sacral spine }\end{array}$ & $\begin{array}{l}\text { Spleen } \\
\text { Thoracic spine } \\
\text { Lumbar/sacral spine }\end{array}$ \\
7 & Incomplete & Diffuse thoracic \\
Incomplete & & Diffuse thoracic \\
\hline
\end{tabular}

Case report (patient 3)

A 40 year old woman had simple mastectomy for breast carcinoma. Four years later, a cervical lymph node metastasis was excised with local irradiation. She was started on tamoxifen and had radiation oophorectomy. Several months later she developed ataxia, diplopia and facial weakness. Cranial CT was normal, but HMFG1-PEM and malignant cells were demonstrated in the CSF. Following intravenous chemotherapy and $3000 \mathrm{cGy}$ of whole brain irradiation, she deteriorated with the development of a complete third nerve palsy, nystagmus, masseter wasting, facial numbness, deafness, bulbar paresis, saddle numbness and loss of deep tendon jerks. Instillation of intraventricular I-131 immunoconjugate was initially uneventful, but 10 days later she developed status epilepticus requiring ventilation. Following the control of seizures she was discharged home. At three months following discharge her neurological status remained unchanged, but lumbar CSF was free of malignant cells and HMFG1-PEM. She subsequently gained weight and improved neurologically. At 18 months following discharge, she had recovered facial sensation and normal gait. Deep tendon jerks had reappeared and saddle numbness had resolved. She remained with a partial third nerve palsy and deafness but was able to continue normal activities independently. At 36 months she remains in remission with absence of malignant cells and HMFG1-PEM in CSF.

\section{Toxicity}

The commonest form of toxicity experienced was an aseptic meningitis manifesting as headaches, nausea, vomiting, nuchal rigidity and pyrexia. This was observed in cases $1,4,5$, and 6 , and in all instances resolved spontaneously over approximately 48 hours.

The fatality of case 2 falls into the category of an acute toxic complication of therapy which occurred at approximately 72 hours after instillation of immunoconjugate. Necropsy studies revealed no obvious cause of her sudden death, but there was circumstantial evidence to suggest that this may have been due to unwitnessed epileptic seizures. Epilepsy was part of her presenting clinical syndrome and 12 hours before her death she had been observed in a transient semi-comatose state lasting approximately 20 minutes. New onset epilepsy was subsequently seen in case 3 at 10 days following administration of immunoconjugate.

Three patients developed bone marrow suppression (cases 1, 3, and 6). In cases 1 and 3, recovery of pancytopenia was spontaneous. The nadir in white cell count occurred at week 5 in patient 1 (WCC: $3.1 \times 10^{9} /$ lit) and week 4 in patient 3 (WCC: $2 \cdot 1 \times 10^{9} /$ lit). A commensurate fall in platelet count was noted, reaching $86 \times 10^{9} /$ lit and $76 \times 10^{9} /$ lit respectively. In both patients a return to normal blood parameters was observed by week 9 . In patient 6 , the development of a severe pancytopenia at four weeks (WCC: $0.8 \times 10^{9} /$ lit; platelets $6 \times$ $10^{9} /$ lit) was accompanied by a gram negative septicaemia requiring parenteral antibiotics 
Table 4 Intrathecal therapy: pretreatment status

\begin{tabular}{|c|c|c|c|c|}
\hline Patient & Prior therapy (CNS) & Disease status (CNS) & Clinical status & $\begin{array}{l}\text { CSF } \\
\text { cytology }\end{array}$ \\
\hline 1 & $\begin{array}{l}\mathrm{C} / \mathrm{S} \text { radiotherapy, IT } \\
\text { chemotherapy }\end{array}$ & Progressive disease on treatment & $\begin{array}{l}\text { Diplopia, paraparesis, urinary } \\
\text { incontinence }\end{array}$ & + \\
\hline $\begin{array}{l}2 \\
3 \\
4 \\
5 \\
6 \\
7\end{array}$ & $\begin{array}{l}\text { VP shunt } \\
\text { Cranial radiotherapy } \\
\text { IT chemotherapy } \\
\text { VP shunt } \\
\text { IT chemotherapy } \\
\text { Cranial radiotherapy }\end{array}$ & $\begin{array}{l}\text { New disease } \\
\text { New disease } \\
\text { Progressive disease on treatment } \\
\text { New disease } \\
\text { Progressive disease on treatment } \\
\text { Progressive disease on treatment }\end{array}$ & $\begin{array}{l}\text { Dementia, epilepsy, limb spasticity } \\
\text { Confusion, multiple cranial nerve palsies } \\
\text { Paraparesis } \\
\text { Headache, backache, meningism } \\
\text { Nausea, vomiting, headache, meningism } \\
\text { Deafness, paraparesis, facial weakness and } \\
\text { numbness }\end{array}$ & $\begin{array}{l}+ \\
+ \\
+ \\
+ \\
+ \\
+\end{array}$ \\
\hline
\end{tabular}

$\mathrm{C} / \mathrm{S}$, craniospinal; IT, intrathecal; VP, ventriculo-peritoneal.

and transfusion of blood products. It was noteworthy that a peripheral blood count before immunoconjugate administration revealed thrombocytopenia (platelets $86 \times$ $10^{9} /$ lit) which may have reflected tumour infiltration of bone marrow. She died at six weeks following therapy and no necropsy was performed.

\section{Discussion}

Carcinomatous meningitis may complicate any form of systemic carcinoma, but the most commonly reported primary tumour sites include breast, ${ }^{26}$ lung, ${ }^{27}$ and gastrointestinal tract. ${ }^{28}$ The disorder is generally associated with a poor prognosis and response to therapy. ${ }^{29}$ Median survival with untreated disease is often reported as four to six weeks, although this may reflect delayed clinical diagnosis. ${ }^{3031}$ The conventional approach to the management of this condition involves intrathecal chemotherapy combined with external beam irradiation to the site of major clinical involvement in the neuraxis. Reported clinical responses are variable, with median survivals ranging from two to 5.8 months..$^{29} 3233$ Survival and therapeutic response data appear consistently more favourable for breast carcinoma ${ }^{34} 35$ than lung carcinoma. ${ }^{27} 36{ }^{37}$ Indeed, survivals of two to three years have been reported in occasional patients with neoplastic meningitis complicating breast carcinoma. ${ }^{29}$ 38-40

Although clinical responses have followed conventional therapeutic methods, the nonspecific nature of these modalities results in severe dose-limiting toxicity and consequent limitations in efficacy. As a possible solution to this therapeutic dilemma, several investigators have advocated the intrathecal instillation of colloidal radioactive gold $^{41}$ or yttriumDTPA. ${ }^{42}$ The short range beta-particle emissions from these radionuclides deposit their radiation energy within leptomeningeal tissues

Table 5 Intrathecal therapy: clinical responses (November 1990)

\begin{tabular}{lllll}
\hline Patient & $\begin{array}{l}\text { Neurological } \\
\text { response }\end{array}$ & $\begin{array}{l}\text { CSF } \\
\text { response }\end{array}$ & $\begin{array}{l}\text { Survival } \\
\text { (months) }\end{array}$ & $\begin{array}{l}\text { Current disease } \\
\text { status (CNS) }\end{array}$ \\
\hline 1 & PR & NR & $7^{\star}$ & - \\
2 & Toxic & Death & D & - \\
3 & PR & CR & 36 & Remission \\
4 & NR & NR & $4^{\star}$ & - \\
5 & NR & NR & $3^{\star}$ & - \\
6 & NR & NR & $1^{\star} 5^{\star}$ & - \\
7 & NR & NR & $5^{\star}$ & \\
\hline
\end{tabular}

CR, complete response; $P R$, partial response; NR, no response.

^Patient dead. D, patient died at 72 hours following injection. whilst sparing the underlying neural parenchyma. Although therapeutic success has been reported with this method, the occurrence of cauda equina neurotoxicity has limited enthusiasm for its use. ${ }^{43}$ It is hoped that linkage of short range emitting radionuclides to monoclonal antibodies may facilitate greater specificity of radiation delivery, with consequent reduction in neurotoxicity.

By our defined criteria, clinical responses were seen in 2/6 evaluable patients (cases 1 and 3). In case 3, a complete CSF response was observed as evidenced by the elimination of malignant cells and soluble HMFG1 (PEM) mucin. In cases $1,4,5$, and 7, CSF HMFG1 (PEM) mucin levels increased over a three month period following therapy and malignant cells persisted. In the same patients, serum levels of HMFG1 (PEM) mucin also increased, indicating progressive systemic disease. It is conceivable that, in these patients, systemic tumour may have continued to seed the leptomeninges following therapy. In "carcinomatous meningitis", stable systemic disease may therefore be a prerequisite for the eradication of leptomeningeal tumour with a single instillation of immunoconjugate. Clinically demonstrated extraneuraxial disease may in itself be stable. In these circumstances intrathecal radioimmunotherapy may provide useful palliation of severely debilitating symptoms and sequential serum estimation of PEM may provide evidence to support the stability of systemic disease. Primary neuroectodermal

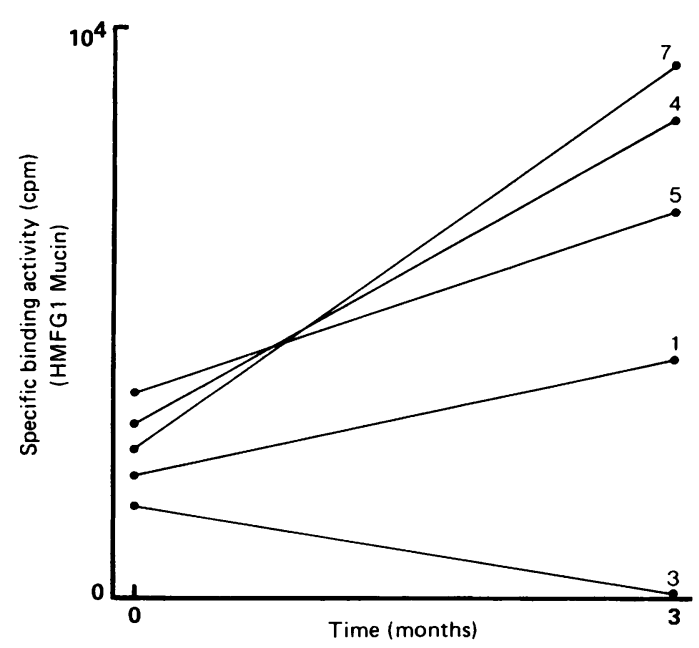

Figure 2 Estimation of CSF HMFG1 (PEM) mucin before and at three months following therapy. 


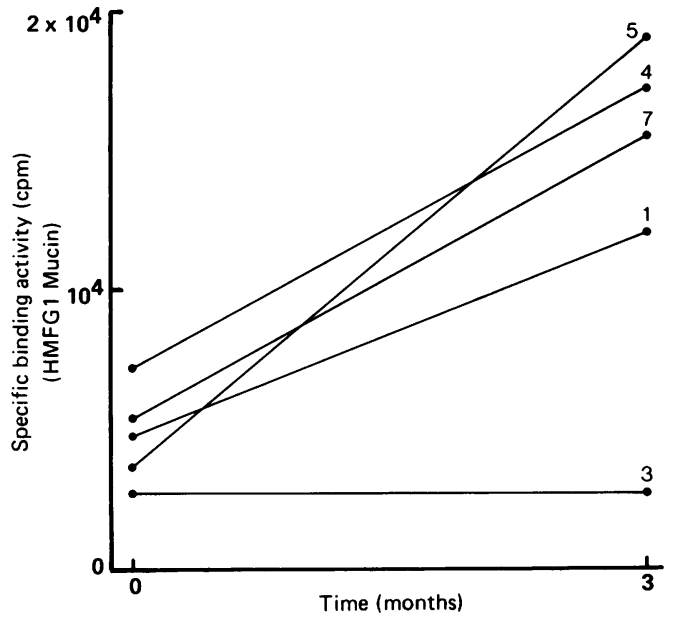

Figure 3 Estimation of serum HMFG1 (PEM) mucin before and at three months following therapy.

meningeal neoplasia may offer a more favourable pathology than that of carcinomatous meningitis as the former is generally more radiosensitive and disease is confined within the central nervous system and therefore theoretically accessible to intrathecally administered immunoconjugate.

In this study, acute toxicity in the form of an aseptic meningitis occurred in over $50 \%$ of patients. Similar toxicity has been reported following intrathecal administration of methotrexate, ${ }^{44}$ cytosine arabinoside ${ }^{45}$ and radioiodinated human serum albumin (RISA). ${ }^{46}$ The reported incidence of aseptic meningitis following intrathecal RISA has been highly variable and this complication has been attributed to contaminating endotoxins. ${ }^{47}$ Aseptic meningitis in our patients was unrelated to administered radioactivity dose and was observed intermittently. It is likely that the presence of contaminating pyrogens accounts for this complication, although radiopharmaceuticals were not tested for their presence. Epilepsy occurred in two patients. We have considered this a toxic response to therapy, but of course seizures occur as a natural event in the disorder. ${ }^{29}$ Delayed central nervous system toxicity has not been observed clinically in long term survivors, but a necropsy study in case 2 revealed extensive periventricular and brainstem sub-pial white matter oedema and astrocytic reaction. ${ }^{48}$ Bone marrow suppression was seen in three patients, and appears to be the dose-limiting toxicity of this form of therapy.

Before dismissing these clinical results as unimpressive, one should consider the devastating nature of this disease. Many of these patients had advanced disease, unresponsive to previous therapy. The important observation here is that therapeutic responses have been demonstrated. As with other forms of oncolytic therapy, clinical results may be more favourable with minimal disease. As leptomeningeal disease progresses, partial obliteration of the subarachnoid space may prevent complete distribution of immunoconjugate throughout the CSF pathways and this clearly reduces the opportunity for therapeutic success. ${ }^{49}$ Emphasis should therefore be placed on the diagnosis of minimal disease and on establishment of complete patency of the craniospinal subarachnoid space before therapy. The addition of Indium-111-DTPA ventriculography may complement CT myelography in this assessment, ${ }^{49}$ and areas of reduced radionuclide distribution may be externally irradiated before intrathecal radioimmunotherapy.

In conclusion, we suggest that intrathecal instillation of monoclonal antibody radioimmunoconjugates may produce a worthwhile clinical response in carcinomatous meningitis, although this may be less marked than that observed in more radiosensitive lymphoid and primary neuroectodermal tumours. Modifications in the methodology may further enhance the therapeutic efficacy of the technique. Firstly, monoclonal antibodies defining alternative epithelium specific antigens might be employed with advantage. A theoretical concern with monoclonal antibody $\mathrm{HMFG1}$ relates to the glycoprotein antigen (PEM) it defines. Polymorphic epithelial mucin (PEM) is liberated from the cell surface into CSF and this may reduce tumour cell targeting of immunoconjugates. ${ }^{14}$ Further variations may include multiple doses, alternative radionuclides or the use of antibody cocktail mixtures to account for heterogeneity of tumour cell antigen expression. ${ }^{50} \mathrm{We}$ believe that intrathecal radioimmunotherapy should be pursued as an alternative method of palliative treatment for carcinomatous meningitis, as presently existing methods of treatment are clinically inadequate. The value of this technique will become more apparent when a larger experience has been accumulated.

This work was performed at Frenchay Hospital, Bristol and was funded by the Bristol Brain Tumour Research Fund, the Imperial Cancer Research Fund, the Preuss Foundation and the Ernest Stanley Luff Trust.

1 Kemshead JT, Coakham HB. The use of monoclonal antibodies for the diagnosis of intercranial malignancies and the small round cell tumours of childhood. J Pathol 1983;141:249-57.

2 Gatter KC, Alcock C, Heryet A, Mason DY. Clinical Importance of Analysing Malignant Tumours of UnImportance of Analysing Malignant Tumours of Un-
certain Origin with Immunohistological Techniques. Lancet 1985;i:1302-5.

3 Larson SM, Carrasquillo JA, Krohn KA, et al. Localisation of I-131-labelled P97-Specific fab fragments in human melanoma as a basis for radiotherapy. J Clin Invest 1983; 72:2101-14.

4 Carrasquillo JA, Krohn KA, Beaumier P, et al. Diagnosis of and therapy for solid tumours with radiolabelled antibodies and immune fragments. Cancer Treat Rep 1984;68: 317-28.

5 Jansen FK, Blythman HE, Carriere D, et al. Immunotoxins: Hybrid Molecules Combining High Specificity and Potent Cytotoxicity. Immunol Rev 1982;62:185-216.

6 Thorpe PE, Brown AN, Bremner JA, Foxwell BM, Stirpe F. An immunotoxin composed of monoclonal anti-thy 1.1 antibody and a ribosome-inactivating protein from antibody and a ribosome-inactivating protein from in vivo. JNCI 1985;75:151-9.

7 Embleton MJ, Rowland GF, Simmonds RG, Jacobs E, Marsden CH, Baldwin RW. Selective cytotoxicity against Marsden $\mathrm{CH}$, Baldwin $\mathrm{RW}$. Selective cytotoxicity against
human tumour cells by a vindesine-monoclonal antibody human tumour cells by a vindesine-m

8 Bourdon MA, Wikstrand CJ, Furthmayr H, Matthews TJ, Bigner DD. Human Glioma-Mesenchymal Extracellular Matrix Antigen Defined by Monoclonal Antibody. Cancer Res 1983;43:2796-805

9 Buchegger F, Mach J-P, Leonnard P, Carrel S. Selective tumour localisation of radiolabelled anti-human melanoma monoclonal antibody fragment demonstrated in the nude mouse model. Cancer 1986;58:655-62.

10 Jones DH, Goldman A, Gordon I, Pritchard J, Gregory BJ, 
Kemshead JT. Therapeutic application of a radiolabelled monoclonal antibody in nude mice xenografted with human neuroblastoma: tumouricidal effects and distribution studies. Int J Cancer 1985;35:715-20.

11 Lee YS, Bullard DE, Zalutsky MR, Coleman RE, Friedman HS, Colapinto EV, Bigner DD. Therapeutic efficacy of murine monoclonal antibody 81C6 in a human glioma xenograft model. Cancer Res 1988;48:559-66.

12 Lee YS, Bullard DE, Humphrey PA, et al. Treatment of intracranial human glioma xenografts with I-131-labelled anti-tenascin monoclonal antibody 81C6. Cancer Res 1988;48:2904-10.

13 Sands H. Radioimmunoconjugates: an overview of problems and promises. Antibody, Immunoconjugates and Radiopharmaceuticals 1988;1:213-26.

14 Zalutsky MR, Knapp RC, Bast RC. Influence of circulating antigen on blood pool activity of a radioiodinated mono-
clonal antibody. Int J Radiat Appl Instrum. (Part B) 1988; clonal antibo

15 Epenetos AA, Hammersmith Hospital Oncology Group, Imperial Cancer Research Fund. Antibody-guided irradiation of malignant lesions: three cases illustrating a new method of treatment. Lancet 1984;i:1441-3.

16 Epenetos AA, Munro AJ, Stewart S, et al. Antibody-guided irradiation of advanced ovarian cancer with intraperitoneally administered radiolabelled monoclonal antibodies. $J$ Clin Oncol 1987;5:1890-9.

17 Pectasides D, Stewart S, Courtenay-Luck N, et al. Antibody-guided irradiation of malignant pleural and pericardial effusions. Br J Cancer 1986;53:727-32.

18 Lashford LS, Davies AG, Richardson RB, et al. A pilot study of 131-I monoclonal antibodies in the therapy of study of 131-I monoclonal antibodies in the the

19 Coakham HB, Richardson RB, Davies AC, Bourne SP, Eckert H, Kemshead JT. Neoplastic meningitis from a pineal tumour treated by antibody-guided irradiation by the intrathecal route. Brit J Neurosurg 1988;2:193-204.

20 Taylor-Papadimitriou J, Peterson JA, Arklie J, Burchall J, Ceriani RJ, Bodmer WF. Monoclonal antibodies to epithelium-specific components of the human milk fat globule membrane: production and reaction with cells in culture. Int J Cancer 1981;28:17-21.

21 Ward BG, Cruickshank DJ. Circulating tumour-associated antigen detected by the monoclonal antibody HMFG2 in human epithelial ovarian cancer. Int $J$ Cancer 1987;39: 30-3.

22 Fraker PJ, Speck JC. Protein and cell membrane iodinations with a sparingly soluble chloroamide $1,3,4,6$-tetrachloro, wa-6a diphenylglucoluril. Biochem Biophys Res Commun 1978;80:849-57.

23 Lindmo T, Boven R, Cuttitta F, Fedorko J, Bunn PA. Determination of the immunoreactive fraction of radiolabelled monoclonal antibodies by linear extrapolaradiolabelled monoclonal antibodies by linear extrapolation to binding at infi
Methods 1984;72:77-89.

24 Lindmo T, Bunn PA. Determination of the true immunoreactive fraction of monoclonal antibodies after radiolabelling. Methods in Enzymology 1986;121:678-91

25 Moseley RP, Oge K, Shafqat S, et al. HMFG1 antigen: a new marker for carcinomatous meningitis. Int $J$ Cancer 1989;44:440-4.

26 Yap H-Y, Yap B-S, Tashima CK, DiStefano A, Blumenschein GR. Meningeal carcinomatosis in breast cancer. Cancer 1978;42:283-6.

27 Aisner J, Ostrow S, Govindan S, Wiernik PH. Leptomeningeal carcinomatosis in small cell carcinoma of the lung. Med Pediatr Oncol 1981;9:47-59.

28 Meissner GR. Carcinoma of the stomach with meningeal carcinosis: report of four cases. Cancer 1953;6:313-8.

29 Wasserstrom WR, Glass JP, Posner JB. Diagnosis and treatment of leptomeningeal metastases from solid treatment of leptomeningeal metastases from solid tumors:
30 Little JR, Dale AJD, Okazaki HMD. Meningeal carcinomatosis-clinical manifestations. Arch Neurol 1974;30: matosis

31 Olson ME, Chernik NL, Posner JB. Infiltration of the leptomeninges by systemic cancer: a clinical and pathological study. Arch Neurol 1974;30:122-37.

32 Shapiro WR, Posner JB, Ushio Y, Chernik NL, Young DE Treatment of meningeal neoplasms. Cancer Treat Rep 1977;61:733-43.

33 Giannone L, Greco FA, Hainsworth JD. Combination intraventricular chemotherapy for meningeal neoplasia. $J$ Clin Oncol 1986;4:68-73.

34 Yap H-Y, Yap B-S, Rasmussen S, Levens ME, Hortobagyi GN, Blumenschein GR. Treatment for meningeal carcinomatosis in breast cancer. Cancer 1982;50:219-22.

35 Schabet M, Kloeter I, Adam T, Heidemann E, Wietholter H. Diagnosis and treatment of meningeal carcinomatosis in ten patients with breast cancer. Euro Neurol 1986;25: in ten patie

36 Aroney RS, Dalley DN, Chan WK, Bell DR, Levi JA. Meningeal carcinomatosis in small cell carcinoma of the lung. Am J Med 1981;71:26-32.

37 Balducci L, Little DD, Khansur T, Steinberg MH. Carcinomatous meningitis in small cell lung cancer. $\mathrm{Am} \mathrm{J} \mathrm{Med}$ Sci 1984;287:31-3.

38 McKelvey EM. Meningeal involvement with metastatic carcinoma of the breast treated with intrathecal methotrexate. Cancer 1968;22:576-80.

39 Posner JB. Management of central nervous system metastases. Semin Oncol 1977;4:81-91.

40 Ongerboer de Visser BW, Somers R, Nooyen WH, Van Heerde $R$, Hart AAM, McVie JG. Intraventricular methotrexate therapy of leptomeningeal metastasis from breast carcinoma. Neurology (Cleveland) 1983;33: breast carci

41 Metz O, Stoll W, Plenert MJ. Meningosis prophylaxis with intrathecal Au-198-Colloid and methotrexate in child-
hood acute lymphocytic leukaemia. Cancer 1982;49: hood acu

42 Smith PHS, Thomas PRO, Steere HA, Beatty HE, Dawson $\mathrm{KB}$, Peckham MJ. Therapeutic irradiation of the central nervous system using intrathecal Y-90-DTPA. $B r J$ Radiol 1976;49:141-7.

43 Gold LHA, Kieffer SA, D'Angio GJ, Fallon VT, Long DM. Current status of intrathecal radiogold in the treatment of medulloblastoma. Acta Radiologica Ther Phys Biol 1972; 11:329-40.

44 Duttera MJ, Bleyer WA, Pomeroy TC, Leventhal CM, Leventhal BG. Irradiation, methotrexate toxicity and the
treatment of meningeal leukaemia. Lancet 1973;ii:703-7.

45 Wang JJ, Pratt CB. Intrathecal arabinosyl cytosine in meningeal leukemia. Cancer 1970;25:531-4.

46 Messert B, Rieder MJ. RISA cisternography: study of spinal fluid changes associated with intrathecal RISA injection. fluid changes associated with
Neurology 1972;22:789-92.

47 Cooper JF, Harbert JC. Endotoxin as cause of aseptic meningitis after radionuclide cisternography. $J$ Nucl Med 1975;16:809-13.

48 Benjamin JC, Moss T, Moseley RP, Maxwell R, Coakham HB. Cerebral distribution of immunoconjugate after treatment for neoplastic meningitis using an intrathecal radiolabelled monoclonal antibody. Neurosurgery 1989; 25:253-8.

49 Grossman SA, Trump DL, Chen DCP, Thompson G, Carmargo EE. Cerebrospinal fluid flow abnormalities in patients with neoplastic meningitis: an evaluation using 1982 ;73: 1982
$641-7$.

50 Wikstrand CJ, Grahmann FC, McComb RD, Bigner DD Antigenic heterogeneity of human anaplastic gliomas and Antigenic heterogeneity of human anaplastic gliomas and glioma-derived cell lines defined by monoclonal
bodies. J Neuropathol Exp Neurol 1985;44:229-41. 